\title{
INTEGRAÇÃO DE PRÁTICAS PARA O MANEJO DE PLANTAS DANINHAS NA CULTURA DO MILHO
}

\section{INTEGRATION OF PRACTICE FOR THE WEED MANAGEMENT IN CORN}

\author{
Alvadi Antonio BALBINOT JUNIOR ${ }^{1}$ \\ Gilcimar Adriano VOGT ${ }^{2}$ \\ Michelangelo Muzell TREZZI ${ }^{3}$
}

\begin{abstract}
RESUMO
As práticas de manejo do solo e de culturas podem afetar diretamente a infestação de plantas daninhas na cultura do milho. $O$ objetivo desse trabalho foi avaliar o efeito da integração de práticas culturais e químicas na infestação de plantas daninhas e na produtividade da cultura do milho. Foi conduzido um experimento em Papanduva, SC, em delineamento experimental de blocos ao acaso, com três repetições e parcelas subdivididas. Nas parcelas foram avaliados dois sistemas de manejo cultural de plantas daninhas: S1 (cultivo de consórcio de espécies para cobertura do solo no inverno, uso de sementes de milho com elevada massa e espaçamento entre fileiras de 0,45 m) e S2 (pousio no inverno, uso de sementes de milho com baixa massa e espaçamento entre fileiras de $0,90 \mathrm{~m}$ ). Nas subparcelas foram avaliadas quatro estratégias de controle de plantas daninhas no milho (sem controle, atrazine, atrazine+mesotrione e capina). Avaliaram-se a quantidade de palha no momento da semeadura do milho, a velocidade de decomposição da palha, a densidade e a massa seca da parte aérea de plantas daninhas e o desempenho da cultura de milho. O uso de práticas culturais para o manejo de plantas daninhas promoveu redução da infestação dessas plantas na cultura de milho, além de aumentar a produtividade da cultura. A aplicação de atrazine + mesotrione proporcionou melhor controle de plantas daninhas e maior produtividade de grãos em relação à aplicação isolada de atrazine.

Palavras-chave: manejo cultural de plantas daninhas; manejo químico de plantas daninhas; interferência; plantio direto; Zea mays.

\section{ABSTRACT}

Soil and crop management can affect the weed population in corn. The experiment was carried out to evaluate the effect of cultural and chemical management practices on weed infestation and corn yield. The experiment was carried out in Papanduva, SC, Brazil. The experimental design was a randomized complete blocks with three replications in a split-plot arrangement. In plots were evaluated two cultural weed management systems: S1 (multicropping of winter cover crops, corn seeds with high weight and narrow row of $0.45 \mathrm{~m}$ ) and S2 (winter fallow, corn seeds with low weight and narrow row of 0.90 $\mathrm{m})$. In subplots were evaluated four weed control strategies (no-control, atrazine, atrazine + mesotrione and weeding). The parameters evaluated were the straw quantity, residue decomposition, weed plant density and shoot dry mass and corn performance. The use of cultural weed management practices reduced the weed infestation on corn and improved the crop yield. The association of atrazine + mesotrione herbicides showed more efficient weed control than atrazine.
\end{abstract}

Key-words: cultural weed management; chemical weed management; interference; no-till; Zea mays.

\footnotetext{
1 Eng. Agr., Dr., pesquisador da Embrapa Soja, Rodovia Carlos João Strass, Distrito de Warta, Londrina, PR, 86001-970, balbinot@cnpso.embrapa.br

$\frac{}{2}$ Eng. Agr., MSc., Epagri/Estação Experimental de Canoinhas, SC, Brasil. E-mail: gilcimar@epagri.sc.gov.br

${ }^{3}$ Eng. Agr., Dr., UTFPR/Campus Pato Branco, Pato Branco, PR, Brasil. E-mail: trezzi@utfpr.edu.br
} 
BALBINOT JR., A.A. et al. Integração de práticas para...

\section{INTRODUÇÃO}

Atualmente, o manejo de plantas daninhas na cultura de milho é realizado predominantemente com herbicidas. No entanto, muitas vezes a utilização inadequada desses produtos ocasiona impactos negativos no ambiente, além de aumentar os custos de produção. A redução do uso desses produtos pode ser obtida com a adoção de medidas preventivas e culturais (Bianchi et al., 2010; Nunes et al., 2010). Dentre as medidas culturais, a utilização de cobertura do solo em sistema de plantio direto é uma prática que apresenta efeitos positivos na supressão de plantas daninhas (Vidal \& Trezzi, 2004; Rizzardi \& Silva, 2006; Theisen \& Bianchi, 2010). Dentre as opções de cobertura do solo de inverno, o consórcio entre espécies poáceas, como azevém e aveia-preta, com espécies fabáceas, como as ervilhacas, pode produzir elevada quantidade de palha, suprimindo a emergência de plantas daninhas, e proporcionar elevadas produtividades de grãos de milho semeado em sucessão (Balbinot Jr. et al., 2007). Além disso, a cobertura do solo com palha flexibiliza o momento adequado para o controle químico das plantas daninhas na cultura do milho, aumentando a sua praticidade de cultivo (Rizzardi \& Silva, 2006).

Outra prática que pode ser usada para reduzir a dependência de herbicidas é o uso de sementes de milho com elevada massa, pois isso pode se refletir em maior velocidade de crescimento inicial e, com isso, aumentar a capacidade da cultura em competir com as plantas daninhas (Balbinot Jr. \& Backes, 2004; Dias et al., 2010). Adicionalmente, outra prática que pode proporcionar vantagem competitiva ao milho em relação às plantas daninhas é a redução do espaçamento entre fileiras de 0,80 a $0,90 \mathrm{~m}$ para 0,45 a $0,50 \mathrm{~m}$. Com essa redução, a cultura ocupa precocemente os recursos do meio (água, luz e nutrientes), sobretudo em genótipos com arquitetura 'moderna' de plantas, melhorando as relações de interferência mútua em favor das plantas cultivadas (Balbinot Jr. \& Fleck, 2005; Trezzi et al., 2008).

No tocante ao controle químico de plantas daninhas na cultura do milho, os herbicidas atrazine e mesotrione são usados com frequência em mistura de tanque, em especial quando há infestações mistas de espécies dicotiledôneas e monocotiledôneas (Creech et al., 2004). No entanto, é possível que em infestações predominantemente de dicotiledôneas e com adoção de práticas culturais de manejo de plantas daninhas se possa realizar o controle apenas com atrazine.

Há carência de informações na literatura sobre os efeitos combinados de práticas culturais para o manejo de plantas daninhas na cultura do milho, como cobertura do solo com palha, sementes com elevada massa e redução do espaçamento entre fileiras. Também não há informações sobre a interação dessas práticas com estratégias químicas e mecânicas de controle de plantas daninhas nessa cultura.

Com a hipótese de que a integração de consórcio para cobertura do solo no inverno, uso de sementes com elevada massa e redução do espaçamento entre fileiras possa reduzir a infestação de plantas daninhas dicotiledôneas na cultura do milho e, consequentemente, diminuir a dependência de herbicidas para obtenção de elevada produtividade de grãos foi realizado o presente trabalho. Portanto, objetivou-se avaliar o efeito da integração de práticas culturais e químicas sobre a infestação de plantas daninhas dicotiledôneas na cultura de milho, assim como sobre a produtividade da cultura.

\section{MATERIAL E MÉTODOS}

Foi conduzido um experimento em Papanduva, SC, na safra 2009/10, em solo classificado como Latossolo Vermelho Distrófico (Embrapa, 1999).

O delineamento experimental utilizado foi o de blocos ao acaso, com três repetições, em parcelas subdivididas. Nas parcelas foram alocados dois sistemas de manejo cultural de plantas daninhas: S1 (cultivo de consórcio de espécies para cobertura do solo no inverno, uso de sementes de milho com elevada massa e espaçamento entre fileiras reduzido) e S2 (pousio no inverno, uso de sementes de milho com baixa massa e espaçamento entre fileiras convencional). Nas subparcelas foram avaliadas quatro estratégias de controle de plantas daninhas no milho (sem controle, atrazine, atrazine + mesotrione e capina). Cada subparcela apresentou área de $21,6 \mathrm{~m}^{2}(3,6 \times 6,0 \mathrm{~m})$, totalizando $86,4 \mathrm{~m}^{2}$ nas parcelas. Como área útil foram considerados $9,0 \mathrm{~m}^{2}$ por subparcela.

A semeadura das culturas para cobertura do solo no S1 foi realizada em maio de 2009 , com uso de semeadora de plantio direto com espaçamento entre fileiras de $0,17 \mathrm{~m}$. Utilizou-se $60 \mathrm{~kg} \mathrm{ha}^{-1} \mathrm{de}$ sementes de aveia-preta, $30 \mathrm{~kg} \mathrm{ha}^{-1}$ de azevém e $30 \mathrm{~kg} \mathrm{ha}^{-1}$ de ervilhaca. No tratamento pousio, praticamente, não houve emergência de plantas espontâneas de inverno oriundas do banco de sementes.

Quinze dias antes da semeadura do milho foi realizada dessecação das plantas com glyphosate $\left(1.440 \mathrm{~g}\right.$ i.a. ha $\left.{ }^{-1}\right)$ mais óleo mineral $\left(1,5 \mathrm{dm}^{3} \mathrm{ha}^{-1}\right)$, aplicados com pulverizador costal, com volume aproximado de $200 \mathrm{dm}^{3} \mathrm{ha}^{-1}$.

No dia 21/10/2009 foi semeado o milho, cultivar SCS155 Catarina, com auxílio de semeadora para plantio direto equipada com facão sulcador. A densidade final foi de 55 mil plantas ha ${ }^{-1}$. No sistema S1, a semente usada teve massa média de 350 $\mathrm{mg}$ e, no S2, $210 \mathrm{mg}$. O espaçamento entre fileiras no S1 foi de $0,45 \mathrm{~m}$ e em S2 foi de $0,90 \mathrm{~m}$.

Quando as plantas de milho apresentavam quatro folhas totalmente expandidas foram realizadas as práticas de controle. Manteve-se um tratamento sem controle (testemunha infestada) e outro capinado. Adicionalmente, testou-se atrazine (2,0 $\mathrm{kg}$ i.a. ha $\left.{ }^{-1}\right)$ e atrazine + mesotrione $(2,0+0,15 \mathrm{~kg}$ i.a. ha ${ }^{-1}$, respectivamente). A aplicação foi realizada com pulverizador costal a pressão constante, com volume de calda equivalente a $200 \mathrm{dm}^{3} \mathrm{ha}^{-1}$. No momento da aplicação dos herbicidas, a temperatura do ar era de $25{ }^{\circ} \mathrm{C}$, ventos fracos, alta luminosidade e ausência de orvalho e chuva após $10 \mathrm{~h}$ da aplicação. 
BALBINOT JR., A.A. et al. Integração de práticas para...

Durante o cultivo do milho, as principais espécies daninhas presentes no experimento foram: guanxuma (Sida spp.), erva-quente (Spermacoce latifolia Aubl.), poaia-branca (Richardia brasiliensis Gomes) e corda-de-viola (Ipomoea hederifolia L.). Não houve infestação de plantas daninhas monocotiledôneas. $O$ controle de pragas e a adubação nitrogenada foram realizados de acordo com as recomendações técnicas.

Nos tratamentos S1 e S2, avaliaram-se a quantidade de palha no momento da semeadura do milho, por meio da coleta de três amostras de $1 \mathrm{~m}^{2}$ em cada parcela; porcentagem de cobertura do solo, avaliada por meio de fotos de acordo com metodologia descrita por Rizzardi \& Fleck (2004); densidade de plantas daninhas, por meio da contagem de plantas presentes em três amostras por parcela com área de $0,25 \mathrm{~m}^{2}$.

Nas subparcelas determinou-se a massa seca de plantas daninhas aos 100 e 130 dias após a semeadura (DAS) do milho, assim como no momento da colheita, em uma amostra de $0,25 \mathrm{~m}^{2}$ em cada subparcela; altura das plantas de milho aos 27 DAS, por meio da medida da distância entre o solo e a maior folha distendida, realizada em 10 plantas por subparcela; altura de plantas na maturação fisiológica; e diâmetro do colmo das plantas de milho no segundo entre nó aos 120 DAS, com paquímetro.

Determinou-se a taxa de decomposição da palha presente no tratamento $\mathrm{S} 1$ aos $28,73,96 \mathrm{e}$ 125 DAS pelo método de bolsas de decomposição (Thomas \& Asakawa, 1993). Quando o milho estava em maturação de colheita, as espigas da área útil foram colhidas e trilhadas. A produtividade de grãos foi corrigida para $13 \%$ de umidade. Os componentes de rendimento (número de espigas por planta, número de grãos por espiga e massa de mil grãos) também foram determinados.

Os dados coletados foram submetidos à análise de variância e ao teste F. Quando constatadas diferenças significativas entre os tratamentos, os mesmos foram comparados pelo teste de Tukey $(p<0,05)$. O programa estatístico utilizado foi o Sisvar (Ferreira, 2000).

\section{RESULTADOS E DISCUSSÃO}

A quantidade de massa seca de palha proporcionada pelo tratamento $\mathrm{S} 1$, no momento da semeadura do milho, foi equivalente a $6,3 \mathrm{t} \mathrm{ha}^{-1}$, enquanto no tratamento $S 2$ foi de apenas $0,8 \mathrm{t} \mathrm{ha}^{-1}$. A porcentagem de cobertura do solo com palha na semeadura do milho em S1 foi de $85 \%$ e no S2 apenas $38 \%$. Em decorrência da menor cobertura do solo com palha e maior espaçamento entre fileiras de milho, a densidade de plantas daninhas em S2, quando o milho estava em estádio de quatro folhas expandidas, foi de 529 plantas $\mathrm{m}^{-2}$, enquanto no $\mathrm{S} 1$ foi de 235 plantas $\mathrm{m}^{-2}$.

A manutenção do solo coberto reduz a emergência de plantas daninhas, o que pode facilitar o controle químico destas na cultura do milho
(Theisen \& Bianchi, 2010). A cobertura morta sobre o solo dificulta a emergência de várias espécies daninhas devido ao efeito físico de sombreamento e à redução da amplitude térmica do solo (Severino \& Christoffoleti, 2001). A palha em decomposição pode liberar compostos químicos, que, por sua vez, podem reduzir a emergência e/ou o crescimento de plantas daninhas (Trezzi \& Vidal, 2004; Souza et al., 2006).

Com base nos dados de taxa de decomposição da palha presente no tratamento S1 (Figura 1), constata-se que, aos 125 DAS, havia, aproximadamente, 2,3 $\mathrm{tha}^{-1}$ de palha sobre o solo, correspondendo a $37 \%$ da palha presente no momento da semeadura do milho. Resultado semelhante foi obtido por Aita \& Giacomini (2003) trabalhando com consórcio de aveia-preta + azevém. Ou seja, no tratamento $\mathrm{S} 1$ houve manutenção de quantidade expressiva de palha até a fase de enchimento de grãos, em decorrência da elevada quantidade inicial de palha $\left(6,3 \mathrm{t} \mathrm{ha}^{-1}\right)$ e da presença de espécies poáceas (aveia-preta e azevém), cuja velocidade de decomposição é, em geral, inferior às fabáceas, devido à alta relação carbono/nitrogênio (Aita \& Giacomini, 2003).

No S1, aos 130 DAS, os tratamentos atrazine, atrazine + mesotrione e capina não diferiram entre si para massa seca da parte aérea de plantas daninhas (Tabela 1). Porém, no tratamento $\mathrm{S} 2$, a aplicação isolada de atrazine proporcionou maior acúmulo de massa seca em relação à aplicação de atrazine + mesotrione e capina. Portanto, na ausência das práticas culturais de manejo, a aplicação isolada de atrazine não foi eficaz no controle. Por outro lado, no S1, com a adoção integrada de práticas culturais de manejo de plantas daninhas houve controle adequado, mesmo quando foi aplicada atrazine isolada. Esse resultado comprova a hipótese inicial do trabalho, de que o uso de técnicas culturais integradas promove menor dependência do controle químico de plantas daninhas.

No tratamento sem controle (testemunha infestada) houve maior acúmulo de massa pelas plantas daninhas no tratamento $\mathrm{S} 2$ em relação ao $\mathrm{S} 1$, o que demonstra os efeitos das práticas culturais na redução da infestação de plantas daninhas na cultura do milho. Contudo, especificamente sobre a redução de espaçamento entre fileiras, os benefícios dessa prática na diminuição de infestação de plantas daninhas podem ser anulados pela maior emergência dessas plantas na linha de plantio, quando há revolvimento expressivo do solo na operação de semeadura (Trezzi et al., 2008).

Em relação à massa seca aérea de plantas daninhas aos 100 DAS e na colheita do milho não foi verificado efeito significativo dos sistemas de manejo de plantas daninhas, ou da interação entre os sistemas de manejo e as estratégias de controle no verão. Contudo, maior massa de plantas daninhas foi observada no tratamento sem controle em relação aos demais (Tabela 2 ). No entanto, a massa seca aérea de plantas daninhas aos 100 DAS no tratamento sem controle não diferiu do tratamento com atrazine. Nessas duas épocas de avaliação 
BALBINOT JR., A.A. et al. Integração de práticas para...

não houve diferença entre a aplicação isolada de

massa de plantas daninhas.

atrazine, atrazine + mesotrione e capina para a

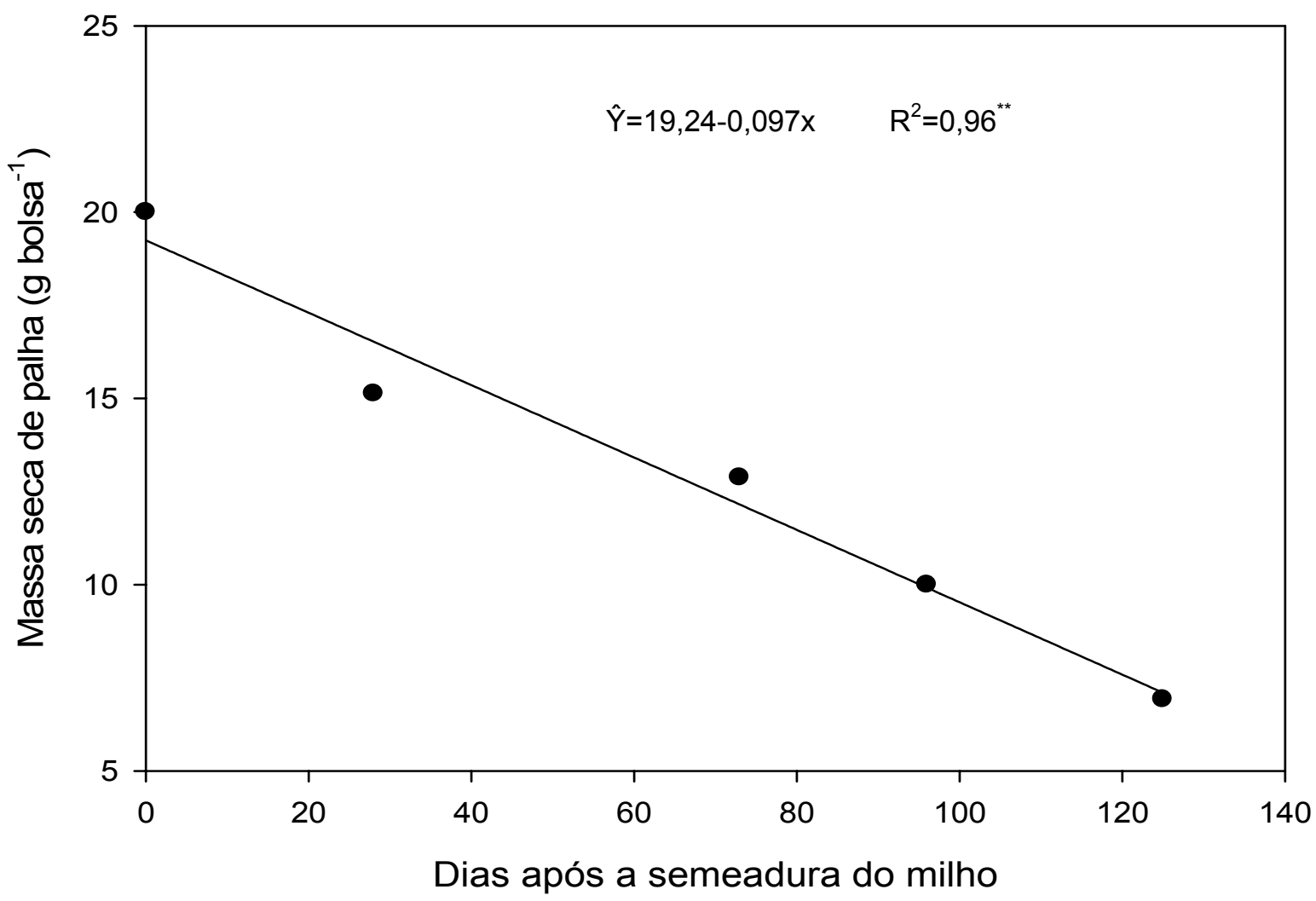

FIGURA 1. Velocidade de decomposição de palha de aveia-preta + ervilhaca + azevém, presente no tratamento $\mathrm{S} 1$ (cultivo de consórcio para cobertura do solo no inverno, espaçamento entre fileiras do milho em $0,45 \mathrm{~m}$ e sementes de elevada massa), durante o desenvolvimento da cultura do milho. ${ }^{* *}$ Significativo a $1 \%$ de probabilidade do erro. Canoinhas, SC, 2010.

TABELA 1. Massa seca da parte aérea de plantas daninhas aos 130 dias após a semeadura do milho (DAS) (g $\mathrm{m}^{-2}$ ), sob diferentes sistemas de manejo e estratégias de controle. Canoinhas, SC, 2010.

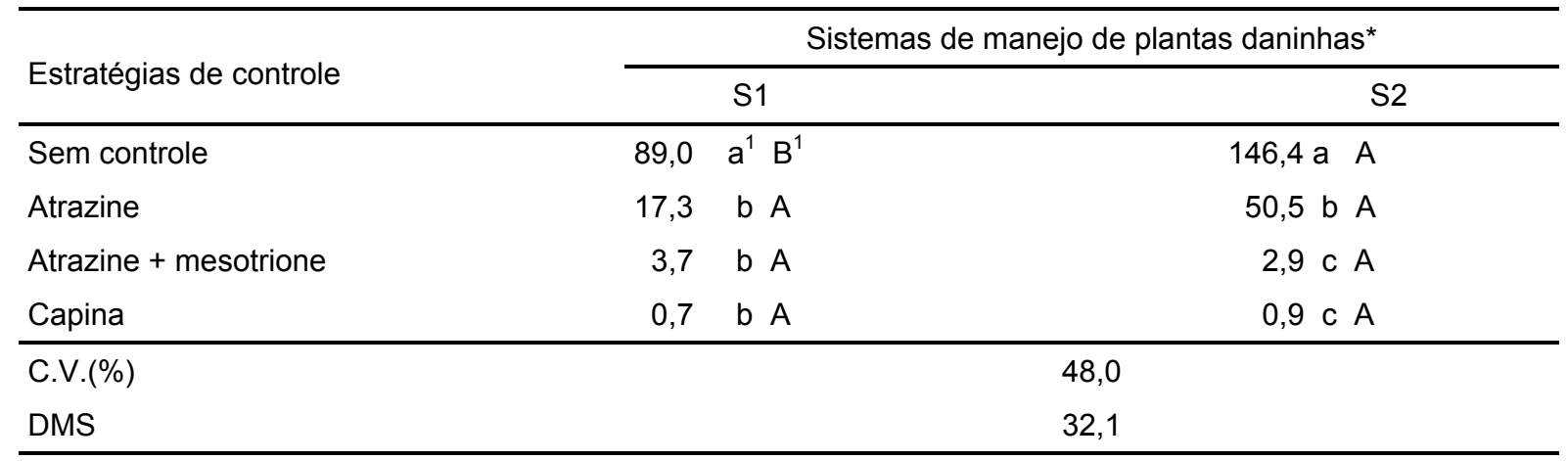

\footnotetext{
${ }^{1}$ Médias seguidas de letras diferentes, minúsculas nas colunas e maiúsculas nas linhas, diferem entre si pelo teste de Tukey a $5 \%$ de probabilidade.

C.V. coeficiente de variação; DMS diferença mínima significativa.

* $\mathrm{S} 1$ cultivo de consórcio para cobertura do solo no inverno, espaçamento entre fileiras do milho em 0,45 m e sementes de elevada massa.

${ }^{*}$ S2 pousio no inverno, espaçamento entre fileiras do milho em $0,90 \mathrm{~m}$ e sementes de baixa massa.
} 
BALBINOT JR., A.A. et al. Integração de práticas para...

TABELA 2. Massa seca da parte aérea de plantas daninhas aos 100 dias após a semeadura do milho (DAS) e no momento da colheita, sob diferentes estratégias de controle (média de dois manejos). Canoinhas, SC, 2010.

\begin{tabular}{lcc}
\hline Estratégias de controle & $\begin{array}{l}\text { Massa seca de plantas da- } \\
\text { ninhas aos 100 DAS }\end{array}$ & $\begin{array}{c}\text { Massa seca de plantas daninhas } \\
\text { na colheita do milho }\end{array}$ \\
\cline { 2 - 3 } & $44,3 \mathrm{a}^{1}$ & $\mathrm{~g} \mathrm{~m}^{-2}$ \\
\hline Sem controle & $22,8 \mathrm{ab}$ & $183,3 \mathrm{a}$ \\
Atrazine & $3,6 \mathrm{~b}$ & $65,7 \mathrm{~b}$ \\
Atrazine + mesotrione & $3,2 \mathrm{~b}$ & $21,8 \mathrm{~b}$ \\
Capina & 57,2 & $19,7 \mathrm{~b}$ \\
\hline C.V.(\%) & 26,5 & 47,3 \\
DMS & 59,0 \\
\hline
\end{tabular}

${ }^{1}$ Médias seguidas de letras diferentes diferem entre si pelo teste de Tukey a $5 \%$ de probabilidade.

C.V. coeficiente de variação; DMS diferença mínima significativa.

As estratégias de controle de plantas daninhas no milho não afetaram nenhuma variável avaliada relacionada ao crescimento das plantas cultivadas (Tabela 3). Esse fato demonstra que a interferência exercida pelas plantas daninhas não ocasionou redução significativa do crescimento das plantas de milho. No caso dos sistemas de manejo cul- tural, houve maior altura de plantas de milho aos 27 DAS no S1 do que no S2 (Tabela 4), o que decorre, provavelmente, da maior massa de sementes de milho usada nesse sistema (Balbinot Jr. \& Backes, 2004). As outras variáveis de crescimento do milho não foram afetadas significativamente pelos sistemas de manejo.

TABELA 3. Altura de plantas de milho e diâmetro do colmo em diferentes estratégias de controle das plantas daninhas (média de dois manejos). Canoinhas, SC, 2010.

\begin{tabular}{lccc}
\hline $\begin{array}{l}\text { Estratégias de contro- } \\
\text { le no verão }\end{array}$ & $\begin{array}{c}\text { Altura de plantas de } \\
\text { milho ao 27 DAS }(\mathrm{cm})\end{array}$ & $\begin{array}{c}\text { Altura de plantas de milho } \\
\text { na maturação fisiológica } \\
(\mathrm{cm})\end{array}$ & $\begin{array}{c}\text { Diâmetro do colmo } \\
(\mathrm{mm})\end{array}$ \\
\hline Sem controle & $50,1^{\mathrm{ns}}$ & $265^{\mathrm{ns}}$ & $26,1^{\text {ns }}$ \\
Atrazine & 52,3 & 269 & 26,9 \\
Atrazine + mesotrione & 52,4 & 262 & 27,9 \\
Capina & 52,5 & 270 & 27,8 \\
\hline C.V.(\%) & 5,4 & 2,7 & 5,3 \\
DMS & 4,8 & 12 & 2,5 \\
\hline
\end{tabular}

${ }^{\mathrm{ns}}$ Diferenças não significativas pelo teste de Tukey a $5 \%$ de probabilidade.

DAS Dias após a semeadura do milho.

C.V. coeficiente de variação; DMS diferença mínima significativa.

O número de espigas por planta e o número de grãos por espiga não foram afetados pelas estratégias de controle (Tabela 5 ) e pelos sistemas de manejo de plantas daninhas (Tabela 6). Isso indica que, no início do desenvolvimento da cultura do milho, a interferência de plantas daninhas não afetou expressivamente a cultura, pois esses dois componentes de rendimento são definidos até o estádio de 12 folhas expandidas (Ritchie \& Hanway, 1992). Por outro lado, a massa de mil grãos e a produtividade foram afetadas pelas estratégias de controle (Tabela 5) e pelos sistemas de manejo (Tabela 6). As estratégias que conferiram maior massa de mil grãos e produtividade foram a capina e o uso de atrazine + mesotrione. Isso ocorreu porque, em geral, foram os tratamentos que proporcionaram melhor controle de plantas daninhas (Tabelas $1 \mathrm{e}$ 2), reduzindo a competição por água, luz e nutrientes. O S1 proporcionou maior massa de mil grãos e produtividade, comparativamente a S2. Possivelmente isso tenha ocorrido porque esse sistema reduziu a infestação de plantas daninhas e porque forneceu à cultura melhores condições de ambiente para a expressão do potencial de rendimento, principalmente, em termos de maior retenção de água no solo, menor amplitude térmica do solo e menor competição intraespecífica, devido ao melhor arranjo espacial de plantas na área. 
BALBINOT JR., A.A. et al. Integração de práticas para...

TABELA 4. Altura de plantas de milho e diâmetro do colmo de plantas de milho sob diferentes manejos de plantas daninhas (média de quatro estratégias de controle). Canoinhas, SC, 2010.

\begin{tabular}{llll}
\hline Manejos & $\begin{array}{l}\text { Altura de plantas de } \\
\text { milho ao 27 DAS }(\mathrm{cm})\end{array}$ & $\begin{array}{l}\text { Altura de plantas de milho } \\
\text { na maturação fisiológica } \\
(\mathrm{cm})\end{array}$ & $\begin{array}{l}\text { Diâmetro do colmo } \\
(\mathrm{mm})\end{array}$ \\
\hline S1 $^{*}$ & $56,1 \mathrm{a}^{1}$ & $271^{\mathrm{ns}}$ & $28,3^{\mathrm{ns}}$ \\
S2* & $47,6 \mathrm{~b}$ & 262 & 26,0 \\
\hline C.V.(\%) & 10,9 & 3,7 & 8,8 \\
DMS & 8,4 & 17 & 4,2 \\
\hline
\end{tabular}

${ }^{1}$ Médias seguidas de letras diferentes diferem entre si pelo teste de Tukey a $5 \%$ de probabilidade.

${ }^{\text {ns }}$ Diferenças não significativas pelo teste de Tukey a $5 \%$ de probabilidade.

C.V. coeficiente de variação; DMS diferença mínima significativa.

DAS Dias após a semeadura do milho.

* S1 cultivo de consórcio para cobertura do solo no inverno, espaçamento entre fileiras do milho em 0,45 m e sementes de elevada massa.

* S2 pousio no inverno, espaçamento entre fileiras do milho em 0,90 m e sementes de baixa massa.

TABELA 5. Componentes de rendimento de grãos de milho e produtividade de grãos sob diferentes estratégias de controle de plantas daninhas (média de dois manejos). Canoinhas, SC, 2010.

\begin{tabular}{|c|c|c|c|c|c|}
\hline $\begin{array}{l}\text { Estratégias de con- } \\
\text { trole no verão }\end{array}$ & $\begin{array}{ll}\text { Número de } & \text { de } \\
\text { espigas por } \\
\text { planta }\end{array}$ & $\begin{array}{l}\text { Número de } \\
\text { grãos por espiga }\end{array}$ & $\begin{array}{l}\text { Massa de mil } \\
\text { grãos }(g)\end{array}$ & $\begin{array}{l}\text { Produtividade } \\
\text { grãos }\left(\mathrm{kg} \mathrm{ha}^{-1}\right)\end{array}$ & de \\
\hline Sem controle & $0,95^{\mathrm{ns}}$ & $428^{n s}$ & $391 b^{1}$ & $7533 b^{1}$ & \\
\hline Atrazine & 1,21 & 451 & $386 b$ & $8156 b$ & \\
\hline $\begin{array}{l}\text { Atrazine + mesotrio- } \\
\text { ne }\end{array}$ & 1,11 & 490 & $401 a b$ & $9455 \mathrm{a}$ & \\
\hline Capina & 1,08 & 447 & $414 a$ & $8528 a b$ & \\
\hline C.V.(\%) & 22,4 & 11,0 & 3,0 & 7,5 & \\
\hline DMS & 0,42 & 86,3 & 21 & 1081 & \\
\hline
\end{tabular}

${ }^{n s}$ Diferenças não significativas pelo teste de Tukey a $5 \%$ de probabilidade.

${ }^{1}$ Médias seguidas de letras diferentes diferem entre si pelo teste de Tukey a $5 \%$ de probabilidade.

C.V. coeficiente de variação; DMS diferença mínima significativa.

TABELA 6. Componentes de rendimento de grãos de milho e produtividade de grãos em diferentes manejos de plantas daninhas (média de quatro estratégias de controle). Canoinhas, SC, 2010.

\begin{tabular}{|c|c|c|c|c|}
\hline Manejos & $\begin{array}{l}\text { Número de } \\
\text { espigas por } \\
\text { planta }\end{array}$ & $\begin{array}{l}\text { Número de } \\
\text { grãos por espiga }\end{array}$ & $\begin{array}{l}\text { Massa de mil } \\
\text { grãos }(g)\end{array}$ & $\begin{array}{l}\text { Produtividade } \\
\text { grãos }\left(\mathrm{kg} \mathrm{ha}^{-1}\right)\end{array}$ \\
\hline$S 1^{*}$ & $1,05^{\mathrm{ns}}$ & $452^{\text {ns }}$ & $414 a^{1}$ & $9569 a$ \\
\hline$S 2^{*}$ & 1,13 & 456 & $382 \mathrm{~b}$ & 7266 b \\
\hline C.V.(\%) & 12,5 & 10,7 & 3,0 & 9,5 \\
\hline DMS & 0,23 & 85,6 & 21 & 1404 \\
\hline
\end{tabular}

${ }^{n s}$ Diferenças não significativas pelo teste de Tukey a $5 \%$ de probabilidade.

${ }^{1}$ Médias seguidas de letras diferentes diferem entre si pelo teste de Tukey a $5 \%$ de probabilidade.

C.V. coeficiente de variação; DMS diferença mínima significativa.

* S1 cultivo de consórcio para cobertura do solo no inverno, espaçamento entre fileiras do milho em 0,45 m e sementes de elevada massa.

* S2 pousio no inverno, espaçamento entre fileiras do milho em 0,90 m e sementes de baixa massa. 
BALBINOT JR., A.A. et al. Integração de práticas para...

\section{CONCLUSÕES}

O uso de práticas culturais para o manejo de plantas daninhas dicotiledôneas promoveu redução da infestação dessas plantas na cultura de miIho, além de aumentar a produtividade da cultura. A aplicação de atrazine + mesotrione proporcionou melhor controle de plantas daninhas dicotiledôneas e maior produtividade de grãos em relação à aplicação isolada de atrazine.

\section{REFERÊNCIAS}

1. AITA, C.; GIACOMINI, S.J. Decomposição e liberação de nitrogênio de resíduos culturais de plantas de cobertura de solo solteiras e consorciadas. Revista Brasileira de Ciência do Solo, v.27, n.4, p.601-612, 2003.

2. BALBINOT JR., A.A.; BACKES, R.L. Crescimento inicial e competitividade do milho com planta concorrente afetados pelo genótipo e massa das sementes. Revista de Ciências Agroveterinárias, v.3, n.1, p.31-37, 2004.

3. BALBINOT JR., A.A.; FLECK, N.G. Manejo de plantas daninhas na cultura de milho em função do arranjo espacial de plantas e características dos genótipos. Ciência Rural, v.35, n.1, p.245-252, 2005

4. BALBINOT JR., A.A. et al. Efeito de coberturas de inverno e sua época de manejo sobre a infestação de plantas daninhas na cultura de milho. Planta Daninha, v.25, n.3, p.473-480, 2007.

5. BIANCHI, M.A. et al. Papéis do arranjo de plantas e do cultivar de soja no resultado da interferência com plantas competidoras. Planta Daninha, v.28, número especial, p.979-991, 2010.

6. CREECH, J.E. et al. Photosynthesis and growth responses of Zea mays L. and four weed species following postemergence treatments with mesotrione and atrazine. Pest Management Science, v.60, n.11, p. 1079-1084, 2004.

7. DIAS, M.A.N. et al. Vigor de sementes de milho associado à mato-competição. Revista Brasileira de Sementes, v.32, n.2, p.93-101, 2010

8. EMBRAPA. Centro Nacional de Pesquisa de Solos. Sistema Brasileiro de Classificação de Solos. Brasília: EMBRAPA 1999. 412 p.

9. FERREIRA, D. F. Análises estatísticas por meio do Sisvar para Windows versão 4.0. In: REUNIÃO ANUAL DA REGIÃO BRASILEIRA DA SOCIEDADE INTERNACIONAL DE BIOMETRIA, 45., São Carlos, 2000. Proceedings... São Carlos, Universidade Federal de São Carlos, 2000. p. 255-258.

10. NUNES, A.L. et al. Manejo integrado de plantas daninhas na cultura do milho. Bragantia, v.69, n.2, p.299-304, 2010.

11. RITCHIE, S.W.; HANWAY, J.J. How a corn plant develops. Ames : lowa State University of Science and Technology, 1992. 26p. (Special Report, 48).

12. RIZZARDI, MA.; FLECK, N.G. Métodos de quantificação da cobertura foliar da infestação de plantas daninhas e da cultura da soja. Ciência Rural, v.34, n.1, p.13-18, 2004.

13. RIZZARDI, M.A.; SILVA, L.F. Influência das coberturas vegetais de aveia-preta e nabo forrageiro na época de controle de plantas daninhas em milho. Planta Daninha, v.24, n.4, p.669-675, 2006.

14. SEVERINO, F.J.; CHRISTOFFOLETI, P.J. Efeitos de quantidades de fitomassa de adubos verdes na supressão de plantas daninhas. Planta Daninha, v.19, n.2, p.223-228, 2001.

15. SOUZA, L.S. et al. Efeito alelopático de capim-braquiária (Brachiaria decumbens) sobre o crescimento inicial de sete espécies de plantas cultivadas. Planta Daninha, v.24, n.4, p.657-668, 2006.

16. THEISEN, G.; BIANCHI, M.A. Semeadura com pouco revolvimento de solo como auxílio no manejo de plantas daninhas em milho. Planta Daninha, v.28, n.1, p.93-102, 2010.

17. THOMAS, R.J.; ASAKAWA, N.M. Decomposition of leaf litter from tropical forage grasses and legumes. Soil Biology \& Biochemistry., v.23, n.10, p.1351-1361, 1993.

18. TREZZI, M.M.; VIDAL, R.A. Potencial de utilização de cobertura vegetal de sorgo e milheto na supressão de plantas daninhas em condição de campo: II - Efeitos da cobertura morta. Planta Daninha, v.22, n.1, p.1-10, 2004.

19. TREZZI, M.M. et al. Manejo químico de plantas daninhas na cultura do milho em função de características morfofisiológicas e redução de espaçamento entre fileiras da cultura. Planta Daninha, v.26, n.4, p.845-853, 2008.

20. VIDAL, R.A.; TREZZI, M.M. Potencial da utilização de coberturas vegetais de sorgo e milheto na supressão de plantas daninhas em condição de campo: I - Plantas em desenvolvimento vegetativo. Planta Daninha, v.22, n.2, p.217-223, 2004.

Recebido em 18/08/2010 Aceito em 11/07/2011 